\title{
Buffer Gas Acquisition and Storage
}

\author{
Clyde F. Parrish ${ }^{1}$, Dale E. Lueck ${ }^{1}$, Paul A. Jennings ${ }^{2}$, Richard A. Callahan ${ }^{3}$ \\ 'Spaceport Engineering and Technology Directorate, YA-D2 \\ NASA John F. Kennedy Space Center, Florida 32899 \\ ${ }^{2}$ Department of Chemical Engineering, Florida Institute of Technology, Melbourne, Florida 32901 \\ ${ }^{3}$ Enerfex, P.O. Box 106130 Commerce St., Williston, Vermont 05495 \\ (321) 867-8763, clyde.parrish-1@ksc.nasa.gov
}

\begin{abstract}
The acquisition and storage of buffer gases (primarily argon and nitrogen) from the Mars atmosphere provides a valuable resource for blanketing and pressurizing fuel tanks and as a buffer gas for breathing air for manned missions. During the acquisition of carbon dioxide $\left(\mathrm{CO}_{2}\right)$, whether by sorption bed or cryo- freezer, the accompanying buffer gases build up in the carbon dioxide acquisition system, reduce the flow of $\mathrm{CO}_{2}$ to the bed, and lower system efficiency. It is this build up of buffer gases that provide a convenient source, which must be removed, for efficient capture of $\mathrm{CO}_{2}$. Removal of this buffer gas barrier greatly improves the charging rate of the $\mathrm{CO}_{2}$ acquisition bed and, thereby, maintains the fuel production rates required for a successful mission. Consequently, the acquisition, purification, and storage of these buffer gases are important goals of ISRU plans. Purity of the buffer gases is a concern e.g., if the $\mathrm{CO}_{2}$ freezer operates at $140 \mathrm{~K}$, the composition of the inert gas would be approximately 21 percent $\mathrm{CO}_{2}, 50$ percent nitrogen, and 29 percent argon. Although there are several approaches that could be used, this effort focused on a hollow-fiber membrane (HFM) separation method. This study measured the permeation rates of $\mathrm{CO}_{2}$, nitrogen $\left(\mathrm{N}_{2}\right)$, and $\operatorname{argon}(\mathrm{Ar})$ through a multiple-membrane system and the individual membranes from room temperature to $193 \mathrm{~K}$ and $10 \mathrm{kPa}$ to $300 \mathrm{kPa}$. Concentrations were measured with a gas chromatograph that used a thermoconductivity (TCD) detector with helium (He) as the carrier gas. The general trend as the temperature was lowered was for the membranes to become more selective. In addition, the relative permeation rates between the three gases changed with temperature. The end result was to provide design parameters that could be used to separate $\mathrm{CO}_{2}$ from $\mathrm{N}_{2}$ and Ar.
\end{abstract}

\section{BACKGROUND}

The major components of the Martian atmosphere are $\mathrm{CO}_{2}(95.5 \%), \mathrm{N}_{2}(2.7 \%)$, and $\mathrm{Ar}(1.6 \%)$ at a pressures from $0.80 \mathrm{kPa}$ to $107 \mathrm{kPa}(0.008 \mathrm{~atm})$. It is proposed to react hydrogen $\left(\mathrm{H}_{2}\right)$ transported to Mars with atmospheric $\mathrm{CO}_{2}$ to produce oxygen $\left(\mathrm{O}_{2}\right)$ and methane $\left(\mathrm{CH}_{4}\right)$. The $\mathrm{O}_{2}$ could then be used for either propulsion or life support. Although primary attention has focused on utilization of $\mathrm{CO}_{2}$, the $\mathrm{N}_{2}$ and $\mathrm{Ar}$ are needed as purge gases or to mix with $\mathrm{O}_{2}$ to form breathing air. Any process for separation of Mars atmospheric gases should be low in weight, low in complexity (maintenance requirements), and low in power consumption. Hollow-fiber membrane separation has the potential to satisfy all of these requirements.

HFM separation has been studied for a number of industrial applications, including recovery of carbon dioxide from combustion processes (Callahan, 1996, 1999) at relatively high temperatures and removal of volatile organic compounds from waste gas streams at lower temperatures. HFMs that can effectively separate $\mathrm{CO}_{2}$ and nitrogen are commercially available. Some commercial membranes can separate $\mathrm{Ar}$ and $\mathrm{N}_{2}$, e.g., the PPA-22 membrane produced by Air Products (Kofron, 2000) will separate them at ambient temperatures and Specialty Silicon Products SSP-M100 dimethyl silicone membrane permeates Ar twice as fast as $\mathrm{N}_{2}$ (Hussey 2000). Li $(1991,1992)$ prepared a series of silicon based inorganic membrane and measured the separation of $\mathrm{Ar}$ and $\mathrm{N}_{2}$ over the temperatures range from $298 \mathrm{~K}$ to $973 \mathrm{~K}$. No studies have yet been published on separation of $\mathrm{Ar}$ and $\mathrm{N}_{2}$ at the low temperatures (193K) encountered on the surface of Mars. Although permeabilities of all gases are expected to decrease with decreasing temperature, design and optimization of separation equipment for use on Mars requires definition of the magnitude of such decreases and any changes in relative permeation that may occur at low temperatures. 
Multiple HFMs sized to match the required product flow will be used to provide a continuous separation process that is similar to those described by Callahan (1999). Once all of the needed data has been collected at low temperatures and pressures, the design of a multi-HFM system can be accomplished.

\section{EXPERIMENTAL METHODS}

Figure 1 is a schematic diagram of the experimental apparatus used in this study. The membrane module used was a hollow-fiber type with feed to the inside of the fibers and permeate withdrawn from the shell surrounding the fiber bundle. Pure gases $\left(\mathrm{CO}_{2} \mathrm{Ar}\right.$, and $\left.\mathrm{N}_{2}\right)$ were combined using a manifold that employed three flow controllers (Sierra) that allowed control of both total flow rate and feed composition. Reject- and permeate-side pressure controllers (MKS Instruments, Inc.) allowed variation of pressure drop across the membrane. The membrane module was enclosed in an insulating box constructed from foamed polystyrene. Temperature was controlled by bleeding liquid nitrogen into the box through a perforated stainless steel tube that distributed the nitrogen along the length of the membrane module. No significant differences were measured between the temperatures of the two effluent streams (i.e., interior of the membrane module) and the temperature inside the box (i.e., exterior of the module). The entire apparatus was installed under a fume hood, which ensured relatively constant ambient temperature conditions.

Flow rates of permeate and reject streams were measured using direct volumetric measurement methods, a wet test meter and/or an electronic bubble meter respectively. The feed flow controllers were calibrated by the KSC NASA calibration laboratory and checked with a wet test meter, and thus flow rates of all streams could be measured as liters per minute at ambient conditions of temperature and pressure (296K and $101 \mathrm{kPa})$. Samples of feed, permeate, and reject gas streams were fed directly to a gas chromatograph through a manifold that allowed real-time sampling of each stream. The gas chromatograph was calibrated by preparing calibration curves based on certified standards.

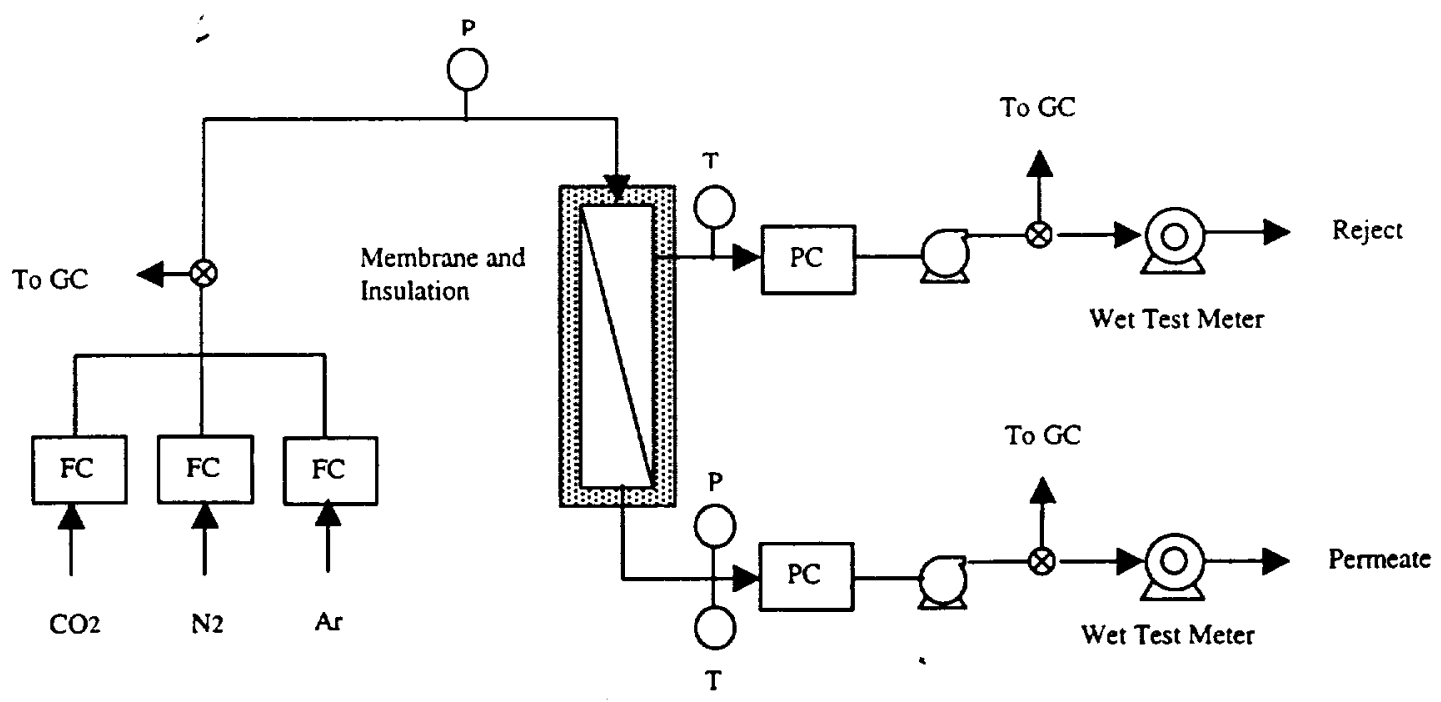

FIGURE 1. Schematic Diagram of the HFM Testbed.

\section{THEORY}

Assuming that ideal plug-flow conditions exist inside each membrane fiber and ideal mixed-flow conditions exist in the "shell" surtounding the fiber bundle, a material balance may be written on an individual fiber in the form:

$$
\frac{d}{d x}\left(F y_{k}\right)+K_{k}\left(p_{k, F}-p_{k, P}\right) a=0
$$


Summing material balances on each component in the system yields an "overall" balance in the form:

$$
\frac{d F}{d x}+\sum_{k} K_{k}\left(p_{k, F}-p_{k, P}\right) a=0
$$

If $\mathrm{L}=$ the length of an individual fiber, a dimensionless axial coordinate may be defined as $z=x / L$. Let $C_{T}{ }^{\circ}=$ total molar concentration at a reference temperature and pressure. A volumetric flow rate may then be defined (in units of volume at the reference conditions per unit time) as $Q=F / C_{T}{ }^{\circ}$. Let $p_{k, F}=P_{F} y_{k, F}$ and $P_{k, P}=P_{P} y_{k, P}$, where $P_{F}$ and $P_{P}$ are the pressures on the feed and permeate sides of the membrane respectively. The material balances may be rewritten in the form:

$$
\begin{aligned}
& \frac{d}{d z}\left(Q y_{k}\right)+\alpha_{k}\left(y_{k, F}-\beta y_{k, P}\right)=0 \\
& \frac{d Q}{d z}+\sum_{k} \alpha_{k}\left(y_{k, F}-\beta y_{k, P}\right)=0
\end{aligned}
$$

Several initial runs were made at room temperature (296K) and with varying flow rates and feed compositions to calibrate analytical equipment. The data obtained was subsequently with the above mathematical model to determine values of permeability for the three compounds in the gas mixture. Values of permeability $(\alpha)$ were found to be $5.67 \times 10^{-5} \mathrm{~m}^{3} \mathrm{~s}^{-1}$ for $\mathrm{CO}_{2}, 2.33 \times 10^{-5} \mathrm{~m}^{3} \mathrm{~s}^{-1}$ for $\mathrm{Ar}$, and $7 \times 10^{-6} \mathrm{~m}^{3} \mathrm{~s}^{-1}$ for $\mathrm{N}_{2}$. Table 1 is a summary of those results. It should be noted that these runs were made before installation of pressure controllers on the feed and permeate. The values of feed-side and permeate side pressures $\left(\mathrm{P}_{\mathrm{F}}\right.$ and $\mathrm{P}_{\mathrm{P}}$ were assumed to be $101 \mathrm{kPa}$ and $1.33 \mathrm{kPa}$ respectively for modeling purposes.

TABLE 1. Room Temperature (296K) Composition Data

\begin{tabular}{lccccc}
\hline \multicolumn{1}{c}{ Property } & Feed & \multicolumn{2}{c}{ Permeate } & \multicolumn{2}{c}{ Reject } \\
& & Measured & Predicted & Measured & Predicted \\
\hline Flow $\left(\mathrm{m}^{3} \mathrm{~s}^{-1}\right)$ & $1.58 \times 10^{-5}$ & $1.35 \mathrm{e} \times 10^{-5}$ & $1.36 \times 10^{-5}$ & $2.31 \times 10^{-6}$ & $2.17 \times 10^{-6}$ \\
$\mathrm{CO}_{2}(\%)$ & 24.1 & 29.6 & 27.9 & 0.2 & 0.4 \\
$\mathrm{Ar}(\%)$ & 31.4 & 33.5 & 35.5 & 6.7 & 5.4 \\
$\mathrm{~N}_{2}(\%)$ & 44.5 & 37.5 & 36.6 & 92.7 & 94.1 \\
$\mathrm{Flow}\left(\mathrm{m}^{3} \mathrm{~s}^{-1}\right)$ & $1.45 \times 10^{-5}$ & $1.27 \times 10^{-5}$ & $1.25 \times 10^{-5}$ & $1.92 \times 10^{-6}$ & $1.98 \times 10^{-6}$ \\
$\mathrm{CO}_{2}(\%)$ & 17.3 & 21.3 & 20.0 & 0.2 & 0.3 \\
$\mathrm{Ar}(\%)$ & 34.2 & 38.9 & 38.9 & 5.2 & 4.8 \\
$\mathrm{~N}_{2}(\%)$ & 48.5 & 40.1 & 41.1 & 94.0 & 94.8 \\
$\mathrm{Flow}\left(\mathrm{m}^{3} \mathrm{~s}^{-1}\right)$ & $1.70 \times 10^{-5}$ & $1.49 \times 10^{-5}$ & $1.47 \times 10^{-5}$ & $2.12 \times 10^{-6}$ & $2.33 \times 10^{-6}$ \\
$\mathrm{CO}_{2}(\%)$ & 29.6 & 36.7 & 34.2 & 0.5 & 0.6 \\
$\mathrm{Ar}(\%)$ & 29.1 & 30.2 & 32.8 & 4.6 & 6.0 \\
$\mathrm{~N}_{2}(\%)$ & 41.3 & 33.4 & 33.0 & 94.2 & 93.4 \\
$\mathrm{Flow}\left(\mathrm{m}^{3} \mathrm{~s}^{-1}\right)$ & $1.93 \times 10^{-5}$ & $1.33 \times 10^{-5}$ & $1.33 \times 10^{-5}$ & $5.45 \times 10^{-6}$ & $6.08 \times 10^{-6}$ \\
$\mathrm{CO} \mathrm{O}_{2}(\%)$ & 19.7 & 30.2 & 28.3 & 0.05 & 0.9 \\
$\mathrm{Ar}(\%)$ & 25.6 & 28.6 & 32.8 & 4.8 & 9.9 \\
$\mathrm{~N}_{2}(\%)$ & 54.7 & 41.7 & 38.8 & 94.5 & 89.2 \\
\hline
\end{tabular}

A set of data was then obtained for a constant feed composition $\left(24.1 \% \mathrm{CO}_{2} 31.4 \% \mathrm{Ar}\right.$, and $\left.44.5 \% \mathrm{~N}_{2}\right)$ and volumetric flow rate $\left(1.58 \times 10^{-5} \mathrm{~m}^{3} \mathrm{~s}^{-1}\right)$ with varying temperature. Temperatures were controlled (by manual adjustment of liquid nitrogen flow) within $\pm 0.5 \mathrm{~K}$ of the values shown. As expected, permeate flow decreased with decreasing temperature. Below $-30^{\circ} \mathrm{C}$; however, permeate flow rates began increasing. Table 2 is a summary of data obtained for temperatures between $243 \mathrm{~K}$ and $296 \mathrm{~K}$. Although permeate flow rates were expected to decrease with decreasing temperature, little change in permeate composition was expected because diffusivities of gases normally show similar dependence upon temperature. (If permeation is a purely diffusive process, the permeation of each compound should decrease with temperature, but the ratio of permeabilities should remain relatively constant.) 
FIGURE 2 is a plot of calculated permeability values as a function of temperature. Although the permeability of each compound decreases with decreasing temperature (as expected), the shape of the curve for $\mathrm{CO}_{2}$ is significantly different from the shape of the curves for $\mathrm{Ar}$ and $\mathrm{N}_{2}$. This may indicate that permeation of carbon dioxide may involve a different mechanism than permeation of argon and nitrogen. In addition, the variation of permeability with temperature implies that temperature may be used as an independently controlled variable to optimize separation in a multiple-stage system. For example, separation of carbon dioxide from nitrogen and argon may be optimal at moderate temperatures ( $263 \mathrm{~K}$ to $273 \mathrm{~K}$ ), while separation of argon from nitrogen may be optimal at relatively high temperatures $(293 \mathrm{~K})$.

TABLE 2. Low Temperature Permeation Data.

\begin{tabular}{lcccccc}
\hline \multicolumn{1}{c}{ Property } & Temperature & \multicolumn{2}{c}{ Permeate } & \multicolumn{2}{c}{ Reject } & Permeability \\
& K & Measured & Predicted & Measured & Predicted & (Lpm) \\
\hline Flow $\left(\mathrm{m}^{3} \mathrm{~s}^{-1}\right)$ & 296 & $1.35 \times 10^{-5}$ & $1.36 \times 10^{-5}$ & $2.31 \times 10^{-6}$ & $2.17 \times 10^{-6}$ & \\
$\mathrm{CO}_{2}(\%)$ & 296 & 29.6 & 27.9 & 0.2 & 0.4 & 3.4 \\
$\mathrm{Ar}(\%)$ & 296 & 33.5 & 35.5 & 6.7 & 5.4 & 1.4 \\
$\mathrm{~N}_{2}(\%)$ & 296 & 37.5 & 36.6 & 92.7 & 94.1 & 0.42 \\
$\mathrm{Flow}\left(\mathrm{m}^{3} \mathrm{~s}^{-1}\right)$ & 273 & 8.17 & 7.97 & & 7.82 & \\
$\mathrm{CO}_{2}(\%)$ & 273 & 48.7 & 46.6 & 1.0 & 1.1 & 3.0 \\
$\mathrm{Ar}(\%)$ & 273 & 27.5 & 28.4 & 34.2 & 34.4 & 0.39 \\
$\mathrm{~N}_{2}(\%)$ & 273 & 22.5 & 24.9 & 64.4 & 64.5 & 0.21 \\
$\mathrm{Flow}\left(\mathrm{m}^{3} \mathrm{~s}^{-1}\right)$ & 263 & $6.5 \times 10^{-6}$ & $6.63 \times 10^{-6}$ & & $9.15 \times 10^{-6}$ & \\
$\mathrm{CO}(\%)$ & 263 & 56.1 & 55.0 & 3.5 & 1.7 & 2.8 \\
$\mathrm{Ar}(\%)$ & 263 & 23.8 & 24.2 & 35.7 & 36.6 & 0.27 \\
$\mathrm{~N}_{2}(\%)$ & 263 & 19.6 & 20.8 & 60.7 & 61.7 & 0.15 \\
$\mathrm{Flow}\left(\mathrm{m}^{3} \mathrm{~s}^{-1}\right)$ & 253 & $5.67 \times 10^{-6}$ & $5.38 \times 10^{-6}$ & & $1.04 \times 10^{-5}$ & \\
$\mathrm{CO}_{2}(\%)$ & 253 & 61.6 & 65.3 & 2.7 & 2.8 & 2.3 \\
$\mathrm{Ar}(\%)$ & 253 & 18.2 & 18.9 & 37.1 & 37.9 & 0.17 \\
$\mathrm{~N}_{2}(\%)$ & 253 & 16.3 & 15.8 & 59.8 & 59.4 & 0.095 \\
$\mathrm{Flow}\left(\mathrm{m}^{3} \mathrm{~s}^{-1}\right)$ & 243 & $5 \times 10^{-6}$ & $4.27 \times 10^{-6}$ & & $1.15 \times 10^{-5}$ & \\
$\mathrm{CO}_{2}(\%)$ & 243 & 68.7 & 68.7 & 7.6 & 7.5 & 1.3 \\
$\mathrm{Ar}(\%)$ & 243 & 14.1 & 16.2 & 37.4 & 37.0 & 0.12 \\
$\mathrm{~N}_{2}(\%)$ & 243 & 14.4 & 14.8 & 56.4 & 55.5 & 0.075 \\
\hline
\end{tabular}

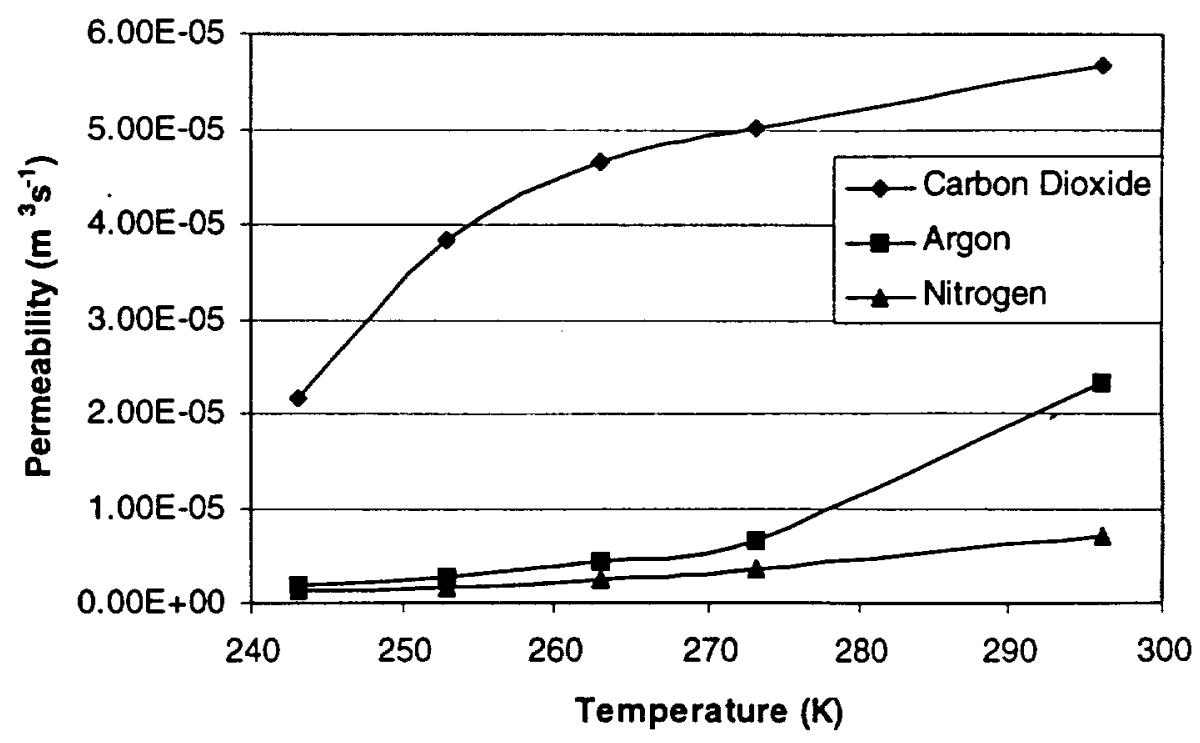

FIGURE 2. Permeability Data. 
Future experiments are planned to obtain additional data for the membrane module used in the above experiments as well as two other modules designed for gas separation. If significant differences in behavior are observed, it may be possible to relate permeation behavior to membrane composition.

The HFMs can be configured before the $\mathrm{CO}_{2}$ capture, after the $\mathrm{CO}_{2}$ capture, or instead of the $\mathrm{CO}_{2}$ capture. Regardless of the configuration, it will be necessary to actively remove the $\mathrm{N}_{2}$ and $\mathrm{Ar}$ from the capture chamber, else the system will become diffusion controlled. The difficulty with diffusion control is that the capture rate is greatly reduced. Therefore, a small compressor or fan would be required to remove the buffer gases. These three configurations are illustrated in FIGURE 3.

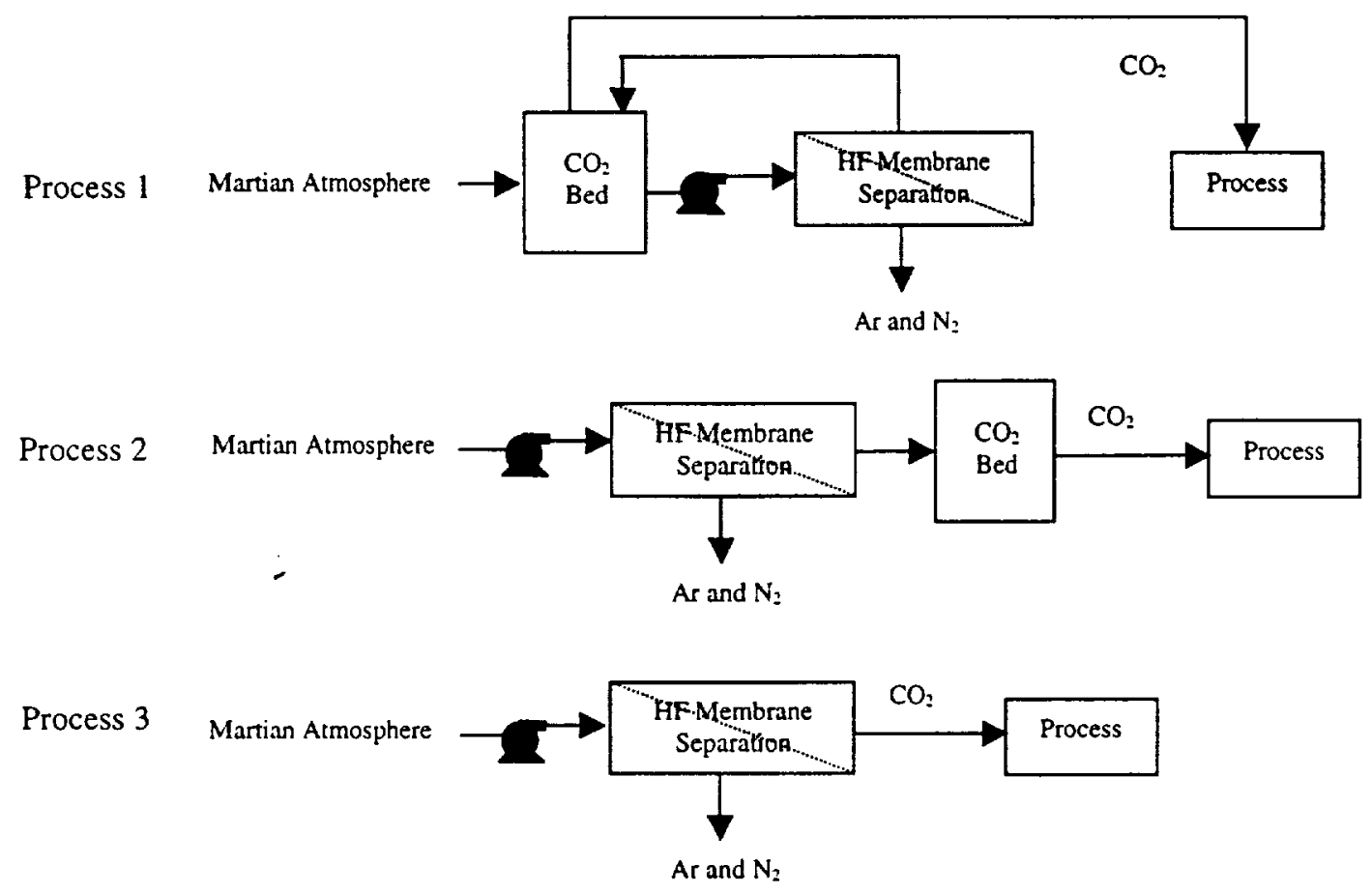

FIGURE 3. Configuration Options for the Capture and Use of Carbon Dioxide.

Each of the configuration options illustrated in FIGURE 3 has certain advantages. For example, Process 1 has a recycle loop, which would return permeate to the $\mathrm{CO}_{2}$ storage/capture section, and would use a smaller compressor. Process 2 would require a larger compressor, but would eliminate the need for a recycle loop. Process 3 eliminates the $\mathrm{CO}_{2}$ capture bed by using a continuous process without the requirement for storage, but it requires that the process can use low-pressure carbon dioxide. Each of these processes require a compressor to assure that the rate of capture of $\mathrm{CO}_{2}$ is sufficient to meet the system needs and they are not diffusion dependent, which can greatly reduce the rate of capture of $\mathrm{CO}_{2}$.

\section{CONCLUSIONS}

An experimental apparatus has been designed, constructed, and tested that allows operation of a membrane module for gas separation with independent control of multiple operating variables: (1) feed flow rate, (2) feed composition, (3) feed pressure, (4) permeate pressure, and (5) operating temperature. Mass flow rates and composition of permeate and reject streams can be independently measured, allowing calculation of percent recovery of each compound in the gas mixture. 
A mathematical model has been derived and tested for the gas separation process under study. It contains one empirical constant ("reduced" permeability) for each component of the gas mixture. which must be evaluated from experimental data. Once the values of these constants are determined, the model is capable of adequately predicting permeate flow rate and composition.

A preliminary analysis of the effects of low temperature operation on permeation rates has demonstrated significant differences in behavior among the three compounds studied. Both flow rate and composition of permeate may be expected to change with temperature as well as pressure. Optimum performance of process equipment may require operation at temperatures significantly greater than the ambient temperature on the Martian surface.

Membrane separation is capable of producing product gas streams with carbon dioxide concentrations well below the maximum contaminant level for breathable air or other applications. Due to low power requirements and simplicity of design and operation, membrane separation appears to be a practical process for a variety of applications of current interest to NASA.

\section{ACKNOWLEDGEMENTS}

We would like to acknowledge the laboratory support provided by Paul Gamble and Lilliana Fitzpatrick of Dynacs Engineering Co., Inc.

\section{NOMENCLATURE}

$\mathrm{a}=$ membrane area per unit length of fiber $(\mathrm{m})$

$\alpha=$ "reduced" permeability (in units of volume at reference conditions per unit time) $=K_{k} P_{F} a L / C_{T}{ }^{0}\left(m^{3} s^{-1}\right)$

$\beta=$ pressure ratio $=P_{P} / P_{F}$

$\mathrm{F}=$ total molar flow rate through the fiber wall $\left(\mathrm{mol} \mathrm{s}^{-1}\right)$

$\mathrm{FC}=$ flow controller

$\mathrm{GC}=$ gas chromatograph

$\mathrm{K}_{\mathrm{k}}=$ permeability of component $\mathrm{k}\left(\mathrm{mol} \mathrm{m} \mathrm{ma}^{-2} \mathrm{P}^{-1}\right)$

$\mathrm{P}=$ pressure transducer

$\mathrm{p}_{\mathrm{k}, \mathrm{F}}=$ partial pressure of component $\mathrm{k}$ on the feed side of the membrane $(\mathrm{Pa})$

$\mathrm{P}_{\mathrm{k}, \mathrm{P}}=$ partial pressure of component $\mathrm{k}$ on the permeate side $(\mathrm{Pa})$

$\mathrm{PC}=$ pressure controller

$\mathrm{T}=$ thermocouple

$\mathrm{x}=$ axial length coordinate $(\mathrm{m})$

$y_{k}=$ mole fraction of component " $k$ "

\section{REFERENCES}

Callahan, Richard, "Multiple Stage Semi-Permeable Membrane Process and Apparatus for Gas Separation," US Patent 5,482,539 (1996).

Callahan, Richard, "Multiple Stage Sermi-Permeable Membrane Process and Apparatus for Gas Separation," US Patent 5,873,928 (1999).

Hussey, John, Specialty Silicon Products, Inc., Curtis Industrial Park, Ballston Spa, NY 12020, (518) 885-8826, private communication (2000).

Kofron, Frank, Air Products, Private communication (2000).

Li, Dong and Hwang, Sun-Tak, "Preparation and Characterization of Silicon Based Inorganic Membranes for Gas Separation," Journal of Membrane Science, 59, 331 -352 (1991).

Li, Dong and Hwang, Sun-Tak, "Gas Separation by Silicon Based Inorganic Membranes at High Temperatures," Journal of Membrane Science, 61, 119-127 (1992). 